\title{
A pilot cohort study of cerebral autoregulation and 2-year neurodevelopmental outcomes in neonates with hypoxic-ischemic encephalopathy who received therapeutic hypothermia
}

Vera Joanna Burton 1,2,3,9* , Gwendolyn Gerner ${ }^{2,4}$, Elizabeth Cristofalo ${ }^{1,2,5}$, Shang-en Chung ${ }^{6}$, Jacky M. Jennings ${ }^{6}$, Charlamaine Parkinson ${ }^{2,5}$, Raymond C. Koehler ${ }^{7}$, Raul Chavez-Valdez ${ }^{2,5}$, Michael V. Johnston ${ }^{1,2,3,8}$, Frances J. Northington ${ }^{2,5}$ and Jennifer K. Lee 2,7

\begin{abstract}
Background: Neurodevelopmental disabilities persist in survivors of neonatal hypoxic-ischemic encephalopathy (HIE) despite treatment with therapeutic hypothermia. Cerebrovascular autoregulation, the mechanism that maintains cerebral perfusion during changes in blood pressure, may influence outcomes. Our objective was to describe the relationship between acute autoregulatory vasoreactivity during treatment and neurodevelopmental outcomes at 2 years of age.
\end{abstract}

Methods: In a pilot study of 28 neonates with $\mathrm{HIE}$, we measured cerebral autoregulatory vasoreactivity with the hemoglobin volume index $(\mathrm{HV} \mathrm{x})$ during therapeutic hypothermia, rewarming, and the first $6 \mathrm{~h}$ of normothermia. The $\mathrm{HVx}$, which is derived from near-infrared spectroscopy, was used to identify the individual optimal mean arterial blood pressure (MAP ${ }_{\mathrm{OPT}}$ ) at which autoregulatory vasoreactivity is greatest. Cognitive and motor neurodevelopmental evaluations were completed in 19 children at 21-32 months of age. MAP ${ }_{\mathrm{OPT}}$, blood pressure in relation to $\mathrm{MAP}_{\mathrm{OPT}}$, blood pressure below gestational age $+5(\mathrm{ga}+5)$, and regional cerebral oximetry $\left(\mathrm{rSO}_{2}\right)$ were compared to the neurodevelopmental outcomes.

Results: Nineteen children who had HIE and were treated with therapeutic hypothermia performed in the average range on cognitive and motor evaluations at 21-32 months of age, although the mean performance was lower than that of published normative samples. Children with impairments at the 2-year evaluation had higher MAP OPT values, spent more time with blood pressure below MAP $\mathrm{OPT}_{\text {, }}$ and had greater blood pressure deviation below MAP ${ }_{\mathrm{OPT}}$ during rewarming in the neonatal period than those without impairments. Greater blood pressure deviation above MAP OPT during rewarming was associated with less disability and higher cognitive scores. No association was observed between $\mathrm{rSO}_{2}$ or blood pressure below ga +5 and neurodevelopmental outcomes.

(Continued on next page)

\footnotetext{
*Correspondence: Burton」@kennedykrieger.org

${ }^{1}$ Neurology and Developmental Medicine, Kennedy Krieger Institute,

Baltimore, MD, USA

${ }^{2}$ Neurosciences Intensive Care Nursery, Johns Hopkins School of Medicine,

Baltimore, MD, USA

Full list of author information is available at the end of the article
}

(c) 2015 Burton et al. Open Access This article is distributed under the terms of the Creative Commons Attribution 4.0 International License (http://creativecommons.org/licenses/by/4.0/, which permits unrestricted use, distribution, and reproduction in any medium, provided you give appropriate credit to the original author(s) and the source, provide a link to the Creative Commons license, and indicate if changes were made. The Creative Commons Public Domain Dedication waiver (http://creativecommons.org/publicdomain/zero/1.0/) applies to the data made available in this article, unless otherwise stated. 
(Continued from previous page)

Conclusion: In this pilot cohort, motor and cognitive impairments at 21-32 months of age were associated with greater blood pressure deviation below MAP OPT during rewarming following therapeutic hypothermia, but not with $\mathrm{rSO}_{2}$ or blood pressure below ga +5 . This suggests that identifying individual neonates' MAP OPT is superior to using hemodynamic goals based on gestational age or $\mathrm{rSO}_{2}$ in the acute management of neonatal HIE.

Keywords: Autoregulation, NIRS, Hypoxic-Ischemic Encephalopathy, Therapeutic Hypothermia, Neurodevelopmental Outcomes

\section{Background}

Neonatal hypoxic-ischemic encephalopathy (HIE) affects approximately 3 in 1000 births and is the most common cause of perinatal brain injury in full-term neonates $[1,2]$. Long-term severe sequelae of neonatal HIE include intellectual disability and cerebral palsy. In children who received therapeutic hypothermia for HIE, the incidence of cerebral palsy is approximately $17 \%$ and the incidence of IQ $<70$ is $27 \%$ [3]. Based on these incidence rates, in the United States, the financial burden of HIE-induced intellectual disabilities exceeds $\$ 3.4$ billion per year, and the costs of HIE-induced cerebral palsy exceed $\$ 1.9$ billion per year [3-5]. Multicenter, randomized controlled trials of therapeutic hypothermia for neonatal HIE demonstrate incomplete neuroprotection. In the Total Body Hypothermia for Neonatal Encephalopathy Trial, $55 \%$ of HIE survivors who received hypothermia had persistent neurologic abnormalities at age 6-7 years, including $21 \%$ with cerebral palsy and $22 \%$ with moderate or severe disabilities [6]. The National Institute of Child Health and Human Development (NICHD) Neonatal Research Network trial of therapeutic hypothermia in HIE found that $35 \%$ of survivors who received hypothermia had moderate or severe disabilities at 6-7 years of age [3]. Therefore, additional modifiable factors and potential adjuvant therapies to hypothermia must be identified to improve neurologic outcomes.

Dysregulated cerebral blood flow may be a key component in secondary neurologic injury in HIE [7]. Cerebrovascular autoregulation maintains relatively constant cerebral blood flow across changes in perfusion pressure. This physiologic mechanism functions within a specific range of blood pressure, and the mean arterial blood pressure (MAP) with optimal autoregulatory function is termed the optimal MAP $\left(\mathrm{MAP}_{\mathrm{OPT}}\right)$. The hemoglobin volume index $(\mathrm{HVx})$ monitors autoregulatory vasoreactivity by correlating changes in arterial blood pressure to changes in relative total tissue hemoglobin ( $\mathrm{rTHb})$, a surrogate measure of cerebral blood volume obtained by near-infrared spectroscopy (NIRS). HVx is based on the premise that autoregulatory vasodilation and vasoconstriction induce changes in cerebral blood volume that are proportional to changes in rTHb [8]. HVx can identify $\mathrm{MAP}_{\mathrm{OPT}}$ in neonates with HIE $[9,10]$. We previously reported that blood pressure deviation below MAP $_{\mathrm{OPT}}$ during rewarming is associated with greater brain injury on MRI in pilot studies of autoregulation during HIE $[9,10]$. However, whether blood pressure autoregulation during therapeutic hypothermia and rewarming in the neonatal period is associated with later neurodevelopmental outcomes remains unknown. Neuroprotective blood pressure ranges for HIE are poorly defined, and many clinicians use regional cerebral oximetry $\left(\mathrm{rSO}_{2}\right)$ or maintain blood pressures at gestational age in weeks $+5 \mathrm{mmHg}(\mathrm{ga}+5)$ to help guide hemodynamic goals in neonates [11].

The goal of this observational pilot study was to describe the relationship between blood pressure autoregulation during therapeutic hypothermia for treatment of neonatal HIE and cognitive and motor neurodevelopmental outcomes at approximately 2 years of age. We hypothesized that 1) greater blood pressure deviation below MAP $_{\mathrm{OPT}}$ would be associated with neurodevelopmental disabilities; 2) the $\mathrm{rSO}_{2}$ would not be associated with disability; and 3) greater time spent with blood pressure below the ga +5 would not be associated with disability. We tested each of these hypotheses by comparing autoregulation measurements made during hypothermia, rewarming, and the first $6 \mathrm{~h}$ of normothermia to neurodevelopmental outcomes of children 2 years later.

\section{Methods}

This study was approved by the Johns Hopkins University (JHU, Baltimore, MD) Institutional Review Board. Written, informed consent for HVx monitoring was obtained from the neonates' parents upon admission to the JHU neonatal intensive care unit (NICU) and again before the 2-year neurodevelopmental follow-up evaluations, which took place at the Kennedy Krieger Institute (KKI, Baltimore, MD). All neonates who were admitted to the NICU between September 2010 and October 2012 were screened for study eligibility, which was based on the diagnosis of HIE according to criteria used by the NICHD Neonatal Research Network's clinical trial of hypothermia in neonatal HIE [12]. Briefly, these infants were diagnosed with moderate to severe 
HIE based on clinical exam and blood gas from the umbilical cord or first hour of life with $\mathrm{pH}<7.15$ or a base deficit $>10 \mathrm{mmol} / \mathrm{L}$. If a blood gas measurement was not available, 10-min Apgar score $<5$ or assisted ventilation for $\geq 10 \mathrm{~min}$ after birth, an acute perinatal event, and moderate to severe encephalopathy were used to diagnose HIE. Additional eligibility criteria for this pilot study included gestational age $\geq 35$ weeks, birth weight $\geq 1800 \mathrm{~g}$, initiation of whole-body cooling within $6 \mathrm{~h}$ of birth, presence of an arterial blood pressure cannula, and a parent who spoke English as the primary language. Neonates who did not have an arterial blood pressure cannula, who had a coagulopathy with active bleeding, or who had congenital anomalies or other diagnoses that could make cooling unsafe were not eligible for the study. Moreover, children who were involved in the foster care system at the time of neurodevelopmental follow-up were ineligible for the study. Seventeen of the children in the current study were part of the cohort in which we previously reported an association between blood pressure autoregulatory vasoreactivity measured by $\mathrm{HVx}$ and brain injuries on MRI [9].

\section{Clinical care in the NICU}

All clinical care was determined by the treating clinicians and by NICU protocol. Neonates received whole-body hypothermia with a cooling blanket (Mul-TBlanket Hyper/Hypothermia Blanket and Mul-T-Pad Temperature Therapy Pad; Gaymar Medi-Therm III, Gaymar Industries, Orchard Park, NY) to a goal rectal temperature of $33.5 \pm 0.5{ }^{\circ} \mathrm{C}$ for $72 \mathrm{~h}$. They were rewarmed over $6 \mathrm{~h}$ (goal $0.5{ }^{\circ} \mathrm{C} / \mathrm{h}$ ) to normothermia $\left(36.5{ }^{\circ} \mathrm{C}\right)$. The clinicians determined the hemodynamic goals, decided when to implement vasoactive or inotropic medications, and selected the sedation regimens. When vasoactive medications were needed, dopamine was initiated followed by dobutamine, epinephrine, or milrinone infusions as necessary. Morphine, fentanyl, or hydromorphone boluses and infusions were used for sedation as necessary. Full montage electroencephalograms (EEGs) were conducted during hypothermia and after rewarming in addition to continuous amplitudeintegrated EEG monitoring (Brainz BRM3 Monitor or CFM Olympic Brainz Monitor, Natus Medical Inc., San Carlos, CA) during hypothermia, rewarming, and the first $6 \mathrm{~h}$ of normothermia. Phenobarbital was administered to treat electrographic or clinical seizures; thereafter, levetiracetam, fosphenytoin, or topiramate was used for persistent seizures. Clinicians could view the $\mathrm{rSO}_{2}$, as measured by the NIRS, and blood pressure, as measured by continuous cardio-respiratory monitors, but they were blinded to HVx. Respiratory support parameters, including nasal cannula, high flow nasal cannula, or ventilator support with endotracheal tube were recorded during the rewarming period. Clinical histories and clinical variables were obtained by chart reviews.

\section{Autoregulation monitoring}

Adhesive, neonatal cerebral oximetry probes were placed bilaterally on the neonates' foreheads and connected to an INVOS 5100 NIRS machine (INVOS; Covidien, Boulder, CO) according to manufacturer guidelines. We synchronously sampled the NIRS signals and arterial blood pressure from the patient hemodynamic monitor at $100 \mathrm{~Hz}$ and processed the data with ICM+ software (Cambridge Enterprises, Cambridge, UK) using a bedside computer. The ICM+ software calculated $\mathrm{HVx}$ using a continuous, moving correlation coefficient between MAP and the rTHb (a surrogate measure of cerebral blood volume obtained by NIRS) after filtering out high-frequency waves from pulse and respiration [8, 13]. Each calculation of HVx incorporated consecutive, paired, 10-s averaged values from 300-s duration, thereby utilizing 30 data points for each $\mathrm{HVx}$ calculation. $\mathrm{HVx}$ is a continuous variable that ranges from -1 to +1 . Negative or near-zero $H V x$ represents functional vasoreactivity (and therefore intact autoregulation) because MAP and rTHb either negatively correlate or are not correlated. When blood pressure decreases and vasoreactivity becomes impaired, HVx becomes positive and approaches +1 because MAP and rTHb positively correlate. We manually removed artifacts in the NIRS and MAP signals (e.g., arterial line flushes), and we excluded data that comprised $<1 \%$ of the recording period as an additional measure to remove artifacts.

The right and left $\mathrm{HVx}$ values were averaged and sorted into $5-\mathrm{mmHg}$ bins of MAP to generate bar graphs. (None of the neonates had unilateral intracranial lesions on follow-up MRI.) We identified the $\mathrm{MAP}_{\mathrm{OPT}}$ in each time period (hypothermia, rewarming, first $6 \mathrm{~h}$ of normothermia) as the bin that had the most negative HVx when the bar graph exhibited an overall trend of increasing $\mathrm{HVx}$ values as MAP deviated from this nadir (Fig. 1a and b). When a nadir in HVx could not be identified, the neonate was coded as having an unidentifiable $\mathrm{MAP}_{\mathrm{OPT}}$ (Fig. 1c and d). These values were identified by an investigator who was blinded to the neurodevelopmental outcome (JKL).

Blood pressure data were analyzed by three methods within each of the three time periods. First, we calculated the amount of time the neonate spent with blood pressure below, at, or above $\mathrm{MAP}_{\mathrm{OPT}}$ and analyzed this as a percentage of the autoregulation monitoring period. Second, we determined the maximal blood pressure deviation below or above $\mathrm{MAP}_{\text {OPT }}[9,10]$. Third, we 

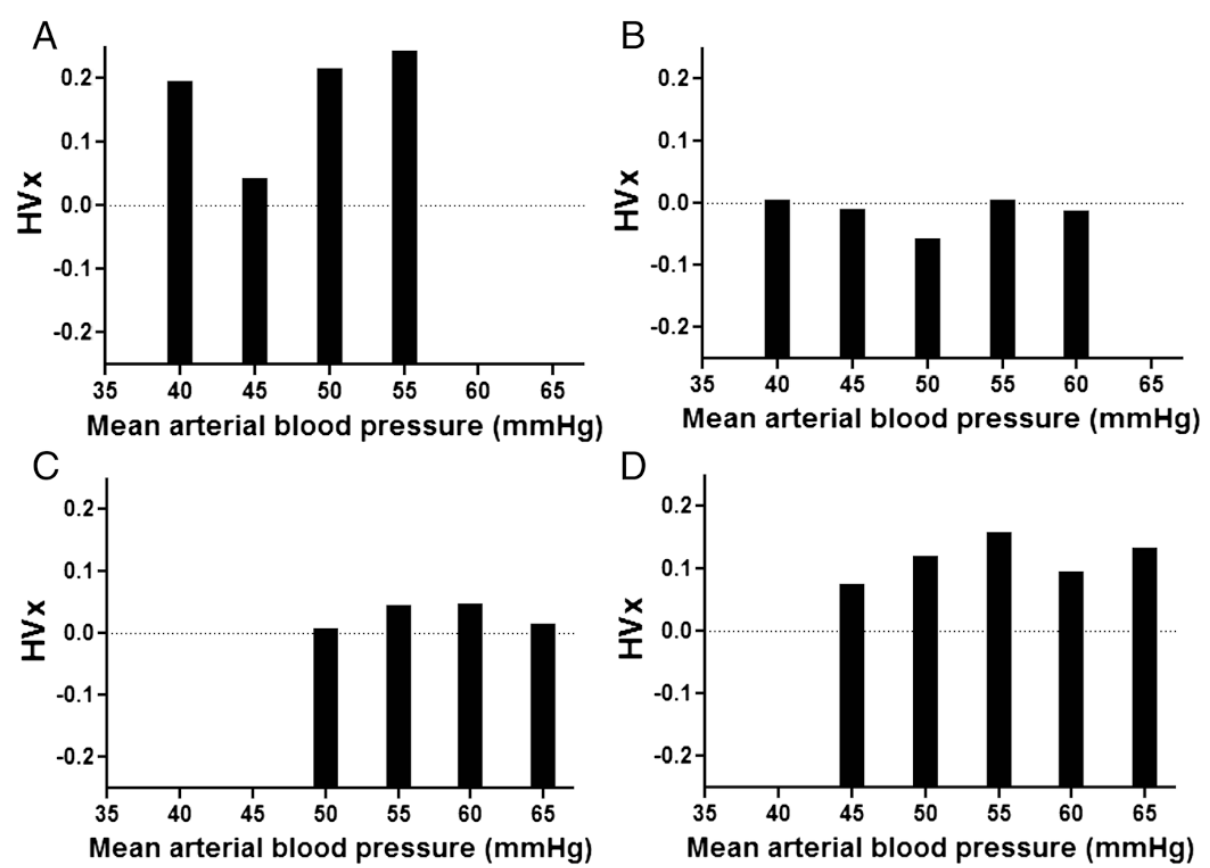

Fig. 1 Representative hemoglobin volume index ( $\mathrm{HVx}$ ) bar graphs from individual neonates illustrate identification of the optimal mean arterial blood pressure (MAP OPT) at the nadir of HVX. MAP OPT values were $45 \mathrm{mmHg}$ for patient 1 (a) and $50 \mathrm{mmHg}$ for patient 2 (b). Patients 5 (c) and 25 (d) did not have a nadir in HVx and were therefore coded as having an unidentifiable MAP OPT

calculated the area under the curve (AUC) to combine the extent of blood pressure deviation below MAP $\mathrm{OPT}$ and the amount of time spent with blood pressure below $\mathrm{MAP}_{\mathrm{OPT}}$. We analyzed time as the absolute duration of autoregulation monitoring to determine the AUC. The AUC $(\min \bullet \mathrm{mmHg} / \mathrm{h})$ was calculated as time (minutes) spent with blood pressure below $\mathrm{MAP}_{\mathrm{OPT}}$ and blood pressure deviation $(\mathrm{mmHg})$ below $\mathrm{MAP}_{\mathrm{OPT}}$, and then normalized for the duration of monitoring (hours) [10]. In addition, we calculated the percentage of time that neonates spent with blood pressure below the ga +5 in each period. Finally, we analyzed the $\mathrm{rSO}_{2}$ using the mean between right and left cerebral hemispheres.

\section{Neurodevelopmental evaluation}

When the children were 21-32 months of age, they were evaluated for neurodevelopmental function in a single visit at KKI during a routinely scheduled clinical visit or a one-time research visit. Clinical visits were part of routine and regularly scheduled care in the KKI NICU follow-up clinic and included a neurologic exam, administration of the Capute Scales [14, 15] completed by or under the supervision of a developmental pediatrician or neonatologist, and a motor evaluation by a physical therapist. The Capute Scales are designed to assess language and visual-motor streams of development in children with a cognitive age $\leq 36$ months. At research visits, the children participated in a battery that included the
Mullen Early Scales of Development and the Gross Motor Function Measure (GMFM) administered by a neuropsychologist or a neurodevelopmental pediatrician. The Mullen is a comprehensive standardized measure of visual perception, language, and motor skill acquisition in children from birth to 68 months of age [16]. The GMFM is a detailed and quantitative measure of gross motor development that is frequently used to evaluate motor skill acquisition in individuals with cerebral palsy [17]. Neurodevelopmental outcomes were classified as impaired based on a Mullen Early Learning Composite Standard Score or Capute Full Scale Developmental Quotient $<85$ and a Gross Motor Function Classification (GMFC) of II-V based on GMFM performance or clinical neurologic and motor exam $[18,19]$. This classification translates functionally to below average cognitive ability and the ability to walk with limitations. In contrast, neurodevelopmental outcomes were classified as unimpaired based on a Mullen Early Learning Composite Standard Score or Capute Full Scale Developmental Quotient $\geq 85$ and a GMFC of I based on GMFM performance or clinical neurologic and motor exam. This classification translates functionally to average cognitive ability and the ability to walk without limitations. Investigators who conducted or supervised the neurodevelopmental examinations (VJB, GG, EC) were blinded to the blood pressure and autoregulation data. 


\section{Statistical analysis}

Data were analyzed with SigmaPlot (v11.0, Systat Software Inc., Chicago, IL) and SAS v9.2 (SAS Institute Inc., Cary, NC). Graphs were generated with GraphPad Prism (v5.03, GraphPad Software Inc., La Jolla, CA). We present the data as means with standard deviations (SD) or medians with interquartile ranges (IQR) when appropriate. Differences were considered significant at $p<0.05$. Neurodevelopmental outcomes were dichotomized into impaired or unimpaired, and the Mullen Early Learning Composite scores were analyzed as a continuous variable. $\mathrm{MAP}_{\mathrm{OPT}}$ values and the percentage of time spent with blood pressure below $\mathrm{MAP}_{\mathrm{OPT}}$ during each period (hypothermia, rewarming, and the first $6 \mathrm{~h}$ of normothermia) were compared by using Wilcoxon signed rank tests. Blood pressure, $\mathrm{MAP}$ OPT, and $\mathrm{rSO}_{2}$ data with respect to neurodevelopmental outcomes were tested separately within each time period. $\mathrm{MAP}_{\mathrm{OPT}}$; the percentage of time spent with blood pressure below, at, or above $\mathrm{MAP}_{\mathrm{OPT}}$; the maximal blood pressure deviation below or above $\mathrm{MAP}_{\mathrm{OPT}}$; $\mathrm{AUC}$; the percentage of time spent with blood pressure below ga +5 ; and $\mathrm{rSO}_{2}$ were compared between children with and without impairments by using Mann Whitney rank sum tests. $\mathrm{MAP}_{\mathrm{OPT}}$, blood pressure data in relation to $\mathrm{MAP}$ OPT and ga +5 , and $\mathrm{rSO}_{2}$ were compared to Mullen scores by using Spearman correlations. Seizure activity and the receipt of a vasopressor (dopamine, dobutamine, or epinephrine) were compared between children with and without impairments by using Fisher exact tests.

\section{Results}

Twenty-eight neonates with HIE received therapeutic hypothermia and had $\mathrm{HVx}$ monitoring. Nineteen of those children participated in neurodevelopmental follow-up examinations at 21-32 months of age. Therefore, data are presented for 19 children (10 girls, 9 boys). Their mean gestational age was 38.9 weeks $(n=19$; $\mathrm{SD}=1.5)$. During the autoregulation monitoring period, $11(58 \%)$ neonates had clinical or electrographic seizures that were treated with phenobarbital. Four of these neonates received additional antiepileptic therapy, including levetiracetam, fosphenytoin, lorazepam, or topiramate for persistent seizures. Thirteen (68 \%) neonates received vasopressors during $\mathrm{HVx}$ monitoring, including 13 with dopamine, four with dobutamine, and one with epinephrine. Morphine infusions were administered to four neonates, and a hydromorphone infusion was given to one neonate. Fourteen neonates were intubated for synchronized intermitted mandatory ventilation (13) or high frequency jet ventilation (1). Seven neonates received nasal continuous positive airway pressure or high-flow nasal cannula respiratory support. During the rewarming period, four intubated neonates had adjustments to their ventilator respiratory rate (range of increase in respiratory rate: $5-14$ breaths $/ \mathrm{min}$ ) or peak inspiratory pressure (range of change in peak inspiratory pressure: 1-6 $\mathrm{cmH}_{2} \mathrm{O}$ ). One neonate had inhaled nitric oxide initiated during rewarming. Nine neonates had adjustments made in the inhaled oxygen concentration delivered through nasal cannula (2), high flow nasal cannula (1), or endotracheal tube (6; range of change in inhaled oxygen concentration: 5-55 \%). No patients received extracorporeal membrane oxygenation (ECMO). Clinical data upon admission to the NICU and physiologic and laboratory data are presented in Tables 1 and 2 .

\section{Neurodevelopmental outcomes}

Nineteen children had neurodevelopmental outcomes evaluated at a median age of 25 months (range, 21-32 months). Fifteen children were evaluated in research visits. Because one of those participants did not complete the GMFM, the GMFC level was determined by using the Mullen Gross Motor performance and clinical judgment. Four children had clinical evaluations. Children who participated in the full research battery had a mean performance on the Mullen Early Learning Composite within the normal range $(n=15$; mean $=88.87$; $\mathrm{SD}=18.52)$. GMFM scores $(n=14 ;$ mean $=84.23$; $\mathrm{SD}=$ 22.57 ) were similar to those of 2-4-year-old children with cerebral palsy who can walk without assistance $(n=25$; mean $=81.2 ; \mathrm{SD}=13.5)$ [18]. The children who had clinical visits also had average mean performance $(n=4$; mean = 86.00; SD = 51.61). Overall, 11 (58 \%) children had typical performance or mild delays in neurodevelopment based on cognitive performance in the average range and the ability to walk without limitations. These 11 children were coded as having an unimpaired neurodevelopmental outcome for the analysis. Eight (42\%) children had more significant delays based on below-average cognitive performance or the inability to walk without limitations. These eight children were coded as having an impaired neurodevelopmental outcome for the analysis. Seizures or

Table 1 Clinical characteristics of neonates with hypoxic-ischemic encephalopathy upon admission to the neonatal intensive care unit

\begin{tabular}{lll}
\hline Parameter & $\mathrm{N}$ & Median (IQR) \\
\hline Apgar at $1 \mathrm{~min}$ & 19 & $1(1,2)$ \\
Apgar at $5 \mathrm{~min}$ & 19 & $3(2,5)$ \\
Apgar at $10 \mathrm{~min}$ & 19 & $5(3,6)$ \\
Cord blood pH & 15 & $7.00(6.91,7.05)$ \\
Cord blood base deficit & 15 & $-11(-10,-15)$ \\
Arterial pH within 1 h of life & 19 & $7.07(6.94,7.24)$ \\
Base deficit within 1 h of life & 19 & $-17(-13,-22)$ \\
\hline
\end{tabular}

$I Q R$ interquartile range 
Table 2 Physiologic and laboratory data during autoregulation monitoring

\begin{tabular}{llll}
\hline Parameter & $\begin{array}{l}\text { Hypothermia } \\
(n=19)\end{array}$ & $\begin{array}{l}\text { Rewarming } \\
(n=17)\end{array}$ & $\begin{array}{l}\text { Normothermia } \\
(n=16)\end{array}$ \\
\hline Temperature $\left({ }^{\circ} \mathrm{C}\right)$ & $33.5(0.5)$ & $35.1(0.9)$ & $36.8(0.3)$ \\
Heart rate $(\mathrm{bpm})$ & $110(17)$ & $117(17)$ & $133(18)$ \\
$\mathrm{pH}^{\mathrm{a}}$ & $7.38(0.05)$ & $7.36(0.07)$ & $7.36(0.06)$ \\
$\mathrm{PaO}_{2}{ }^{a}$ & $130(72)$ & $100(42)$ & $121(50)$ \\
$\mathrm{PaCO}_{2}{ }^{a}$ & $43(8)$ & $50(10)$ & $48(6)$ \\
Hemoglobin $(\mathrm{g} / \mathrm{dL})^{\mathrm{a}}$ & $15.7(2.1)$ & $14.0(0.5)$ & $13.5(0.7)$ \\
\hline
\end{tabular}

All values are presented as mean (SD)

Bpm beats per minute

${ }^{a}$ Arterial blood gas

the receipt of a vasopressor were not associated with having an impaired neurodevelopmental outcome $(p=1.000$ for seizures; $p=1.000$ for vasopressors).

\section{Autoregulatory vasoreactivity}

All 19 neonates with measured neurodevelopmental outcomes were monitored during therapeutic hypothermia. $\mathrm{HVx}$ monitoring was terminated before rewarming in one neonate because of technical complications with monitoring and in a second who was transferred to the pediatric ICU for potential ECMO (ECMO was not initiated). One neonate did not receive $\mathrm{HVx}$ monitoring during normothermia because the arterial blood pressure cannula was removed. $\mathrm{MAP}_{\mathrm{OPT}}$ was identified in 15/19 (79 \%) neonates during hypothermia, 17/17 (100\%) during rewarming, and 14/16 (88\%) during the first $6 \mathrm{~h}$ of normothermia. HVx was monitored for a median of $30.5 \mathrm{~h}$ (IQR, 22.4-46.5) during hypothermia, $6.5 \mathrm{~h}$ (IQR, 5-8) during rewarming, and $6 \mathrm{~h}$ (IQR, 6-6) during normothermia. $\mathrm{MAP}_{\mathrm{OPT}}$ ranged from 35 to $65 \mathrm{mmHg}$, with the majority of $\mathrm{MAP}_{\mathrm{OPT}}$ values between 45 and $55 \mathrm{mmHg}$. Values for $\mathrm{MAP}_{\mathrm{OPT}}$ were similar during hypothermia, rewarming, and the first $6 \mathrm{~h}$ of normothermia ( $p=0.831$ for hypothermia vs. rewarming; $p=0.313$ for hypothermia vs. normothermia; and $p=0.685$ for rewarming vs. normothermia; Fig. 2).

The MAP ranged from 30 to $70 \mathrm{mmHg}$ but remained between 40 and $60 \mathrm{mmHg}$ most of the time (Fig. 3). The percentage of time that neonates spent with blood pressure below $\mathrm{MAP}_{\mathrm{OPT}}$ was similar between time periods. More specifically, neonates spent a median of $6 \%$ (IQR, $1-25$ ) of the hypothermia period and $41 \%$ (IQR, 8-59) of the rewarming period with blood pressure below MAP $\mathrm{OPT}$ $(p=0.119)$. Neonates spent a median of $31 \%$ (IQR, 0$87 \%)$ of the normothermia period with blood pressure below $\mathrm{MAP}_{\mathrm{OPT}}(p=0.083$ for hypothermia vs. normothermia; $p=0.903$ for rewarming vs. normothermia).

Values for $\mathrm{MAP}_{\mathrm{OPT}}$ during rewarming were significantly higher among children who developed impairments

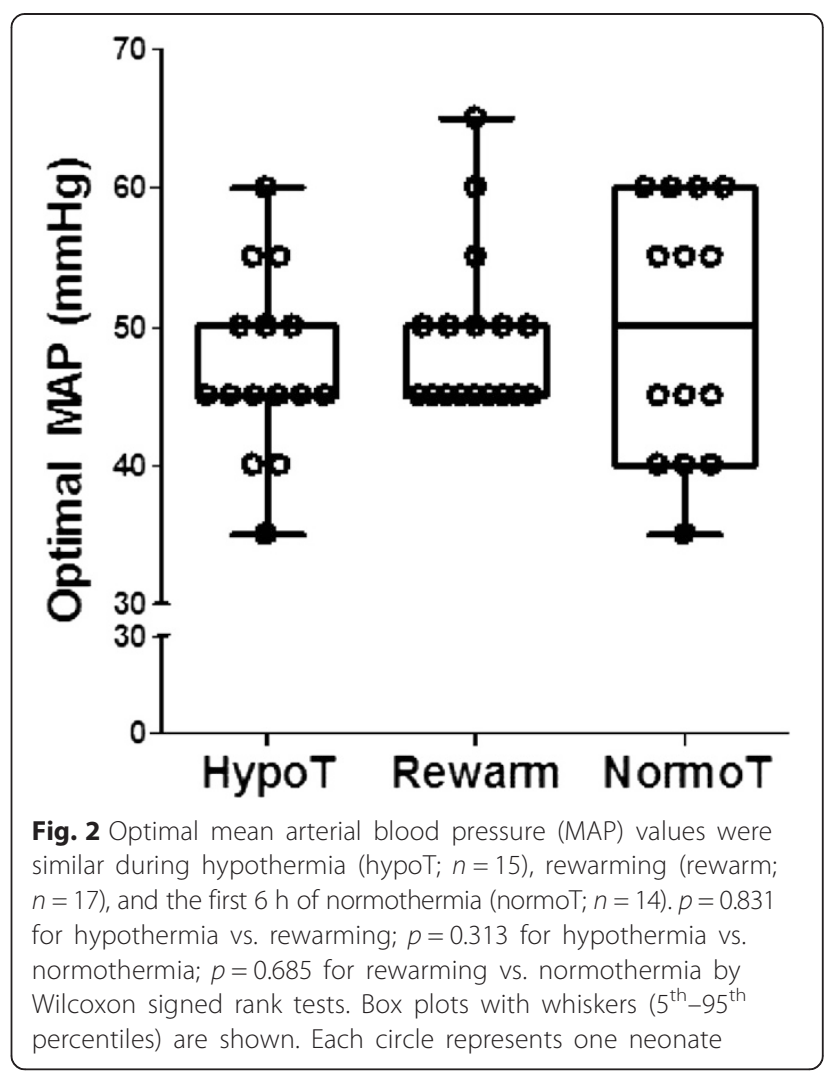

$(n=8)$ than in those who were unimpaired $(n=9 ; p=$ 0.023; Fig. 4a). MAP ${ }_{\text {OPT }}$ values were similar between children with impairments $(n=5)$ and those without impairments during hypothermia $(n=10 ; p=0.949)$ and during normothermia ( $n=7$ children with impairments; $n=7$ children without impairments; $p=0.383$ ).

Neurodevelopmental outcome of children at approximately 2 years was associated with a longer duration of blood pressure below the individual neonate's MAP ${ }_{\mathrm{OPT}}$ during the neonatal rewarming period. Children who developed impairments $(n=8)$ spent a greater percentage of time with blood pressure below $\mathrm{MAP}_{\mathrm{OPT}}$ than did children without impairments $(n=9 ; p=0.048$; Fig. $4 \mathrm{~b})$. Additionally, children with impairments $(n=8)$ had greater maximal blood pressure deviation below MAP ${ }_{\mathrm{OPT}}$ $(p=0.019$; Fig. $4 \mathrm{c})$ and greater AUC below MAP $\mathrm{OPT}$ ( $p=0.039$; Fig. 4d) during rewarming than did those without impairments $(n=9)$. No associations were identified between impairment at 2 years and the percentage of time spent with blood pressure below MAP ${ }_{\mathrm{OPT}}$, maximal blood pressure deviation below $\mathrm{MAP}_{\mathrm{OPT}}$, or AUC during hypothermia and normothermia $(p>0.10$ for all comparisons; Additional file 1: Table S1).

Better neurodevelopmental outcome was associated with greater time spent with blood pressure above $\mathrm{MAP}_{\mathrm{OPT}}$ and greater blood pressure deviation above $\mathrm{MAP}_{\mathrm{OPT}}$ during rewarming. Children who developed 


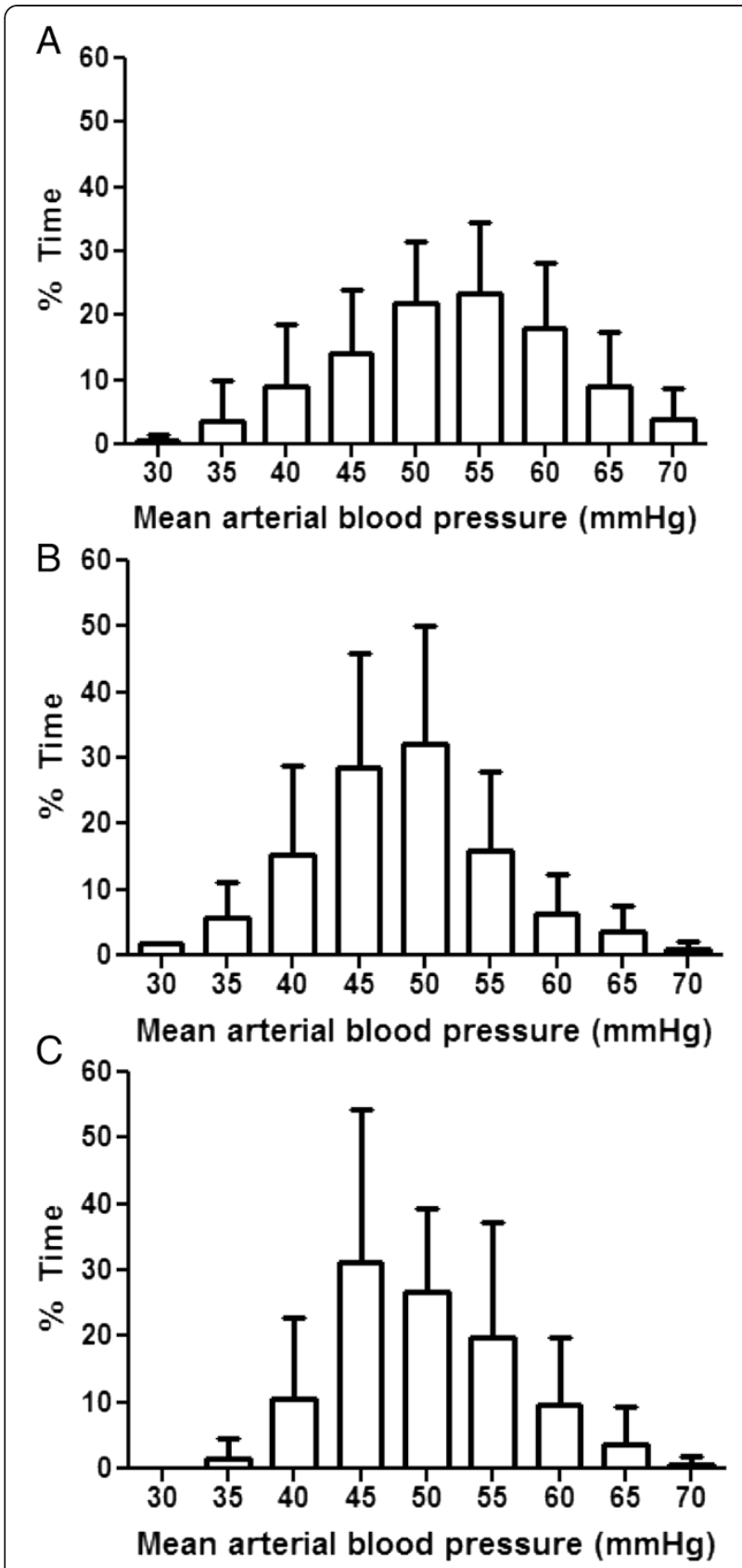

Fig. 3 The percentages of time during hypothermia $(n=19$; a), rewarming $(n=17 ; \mathbf{b})$, and normothermia $(n=16 ; \mathbf{c})$ that neonates spent at each level of mean arterial blood pressure. Data are shown as means with SDs

impairments $(n=8)$ spent a smaller percentage of the rewarming period with blood pressure above $\mathrm{MAP}_{\mathrm{OPT}}$ $(p=0.039$; Fig. 5a) and had less maximal blood pressure deviation above MAP $_{\mathrm{OPT}}(p=0.021$; Fig. $5 \mathrm{~b})$ than did children without impairments $(n=9)$. This association was not present for hypothermia or normothermia ( $p>0.10$ for all comparisons; Additional file 1: Table S1). Moreover, disability was not associated with the percentage of time spent with blood pressure at $\mathrm{MAP}_{\mathrm{OPT}}$ in any time period $(p>0.10$ for all comparisons; Additional file 1: Table S1).

The Mullen score at the 2-year evaluation also correlated with blood pressure in relation to $\mathrm{MAP}_{\mathrm{OPT}}$ during the neonatal rewarming period. A higher Mullen score correlated with a greater percentage of time spent in the rewarming period with blood pressure above $\mathrm{MAP}_{\mathrm{OPT}}$ $(n=13 ; \mathrm{r}=0.560, p=0.044$; Fig. $6 \mathrm{a})$ and a greater maximal blood pressure deviation above MAP $\mathrm{OPT}$ during rewarming $(n=13 ; r=0.585 ; p=0.035$; Fig. $6 b)$. Similarly, maximal blood pressure deviation below MAP ${ }_{\mathrm{OPT}}$ during rewarming and the Mullen score were negatively correlated $(n=13 ; \mathrm{r}=-0.563 ; p=0.044 ;$ Fig. $6 \mathrm{c})$. The proportion of the rewarming period spent with blood pressure below MAP ${ }_{\text {OPT }}$ did not correlate with the Mullen score $(n=13 ; \mathrm{r}=-0.465 p=0.102)$. No correlations were identified between the Mullen score and duration of time with blood pressure above or below MAP ${ }_{\mathrm{OPT}}$ or blood pressure deviation from $\mathrm{MAP}_{\mathrm{OPT}}$ during hypothermia or normothermia $(p>0.10$ for all comparisons; Additional file 2: Table S2). The Mullen score also did not correlate with the percentage of time spent at $\mathrm{MAP}_{\mathrm{OPT}}$ or with the AUC below $\mathrm{MAP}_{\mathrm{OPT}}$ in any time period ( $p>0.05$ for all comparisons; Additional file 2: Table S2).

\section{Cerebral oximetry and blood pressure in relation to gestational age}

When all children were analyzed (including those with an unidentifiable $\mathrm{MAP}{ }_{\mathrm{OPT}}$ ), the mean $\mathrm{rSO}_{2}$ in any period (hypothermia, rewarming, or normothermia) was not associated with future impairment or Mullen score ( $p>0.10$ for all comparisons; Additional file 1: Tables S1 and Additional file 2: Table S2). The percentages of time during the hypothermia, rewarming, and normothermia periods that neonates spent with blood pressure below ga +5 also were not associated with future impairment or Mullen score $(p>0.10$ for all comparisons; Additional file 1: Table S1 and Additional file 2: Table S2). Moreover, neonates spent little time with blood pressure below their gestational age (Fig. 3).

\section{Discussion}

Several findings relevant to the treatment of neonatal HIE are suggested by this observational pilot study. The range of MAP with optimized cerebrovascular autoregulatory vasoreactivity may be identified by using $\mathrm{HVx}$. Further, deviation from $\mathrm{MAP}_{\mathrm{OPT}}$ during rewarming was associated with outcome. Children with impairments at approximately 2 years of age had significantly higher $\mathrm{MAP}_{\mathrm{OPT}}$ values during the neonatal rewarming period than did children without impairments. Neurodevelopmental impairment in children was associated with 

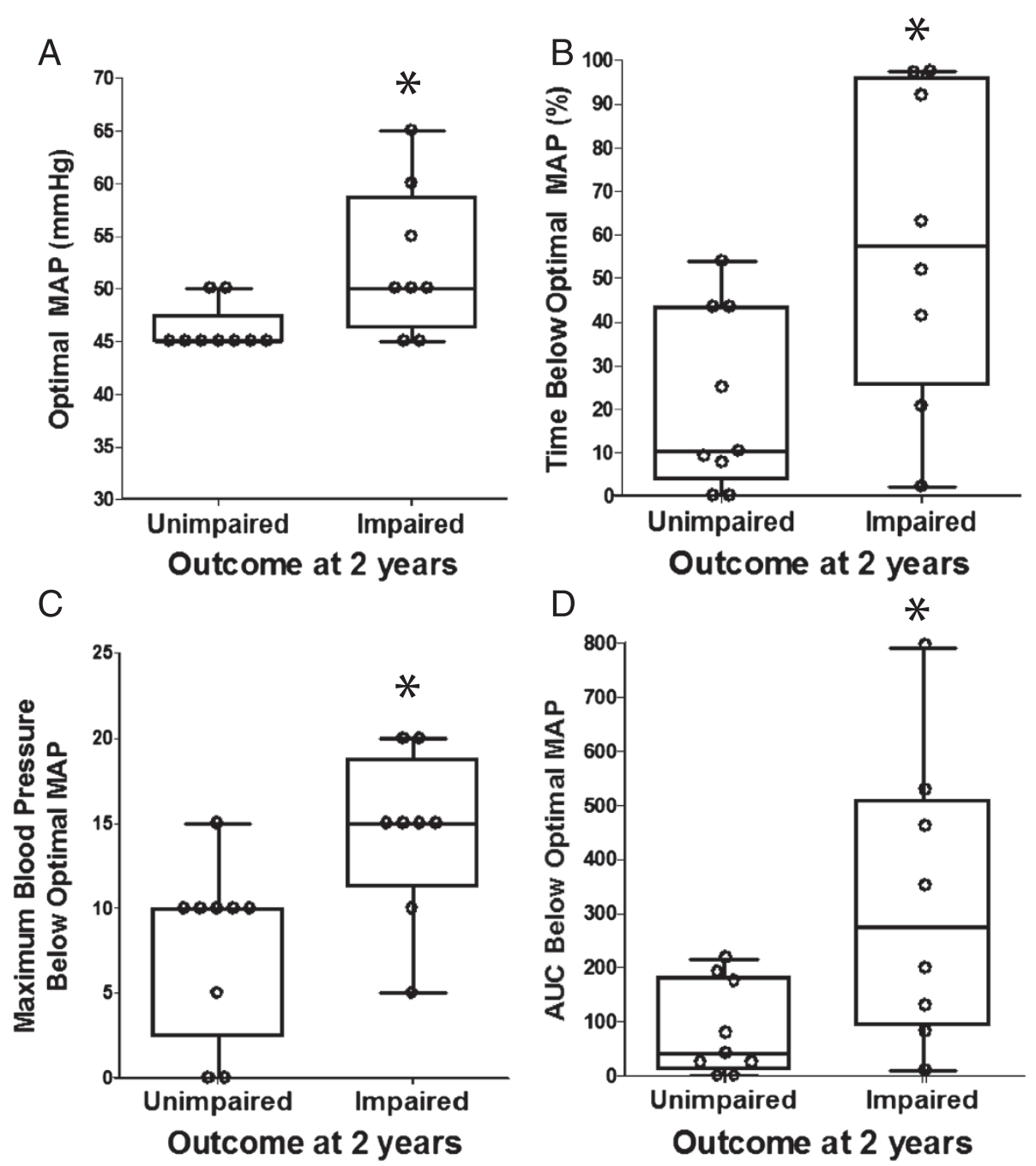

Fig. 4 Optimal mean arterial blood pressure (MAP) and blood pressure below optimal MAP during the neonatal rewarming period in relation to neurodevelopmental outcome at approximately 2 years of age. In comparison to children without impairments $(n=9$; unimpaired), children who developed impairments ( $n=8$; impaired) had higher optimal MAP values ${ }^{*} p=0.023$; $\mathbf{a}$ ), spent a greater percentage of time with blood pressure below optimal MAP $\left({ }^{*} p=0.048 ; \mathbf{b}\right)$, had greater maximal blood pressure deviation below optimal MAP $\left({ }^{*} p=0.019 ; \mathbf{c}\right)$, and had greater area under the curve (AUC) below optimal MAP $\left({ }^{*} p=0.039\right.$; d) during rewarming. Data were analyzed by Mann Whitney rank sum tests. Box plots with whiskers $\left(5^{\text {th }}-95^{\text {th }}\right.$ percentiles) are shown. Each circle represents one child

more time spent at blood pressure below $\mathrm{MAP}_{\mathrm{OPT}}$, having greater maximal blood pressure deviation below $\mathrm{MAP}_{\mathrm{OPT}}$, and having greater AUC below MAP $\mathrm{OPT}$ during the rewarming period. Children without impairments spent more time with blood pressure above $\mathrm{MAP}_{\mathrm{OPT}}$ and had greater blood pressure deviation above MAP $_{\mathrm{OPT}}$ during rewarming than did those with impairments. Furthermore, higher Mullen scores at 2 years significantly correlated with neonates spending more time with blood pressure above $\mathrm{MAP}_{\mathrm{OPT}}$ and having greater blood pressure deviation above $\mathrm{MAP}_{\mathrm{OPT}}$ during rewarming. An association was observed only between neurodevelopmental outcome and blood pressure in relation to $\mathrm{MAP}_{\mathrm{OPT}}$ during rewarming; no association was apparent between outcome and blood pressure during hypothermia or normothermia. Finally, neither the $\mathrm{rSO}_{2}$ nor time spent with blood pressure below ga +5 during hypothermia, rewarming, or normothermia was associated with neurodevelopmental outcome. Although a causal relationship between blood pressure autoregulation and neurodevelopmental outcomes cannot be determined in this small, observational pilot study, our findings reveal an association between better neurodevelopmental outcomes and having blood pressures that remain within or above $\mathrm{MAP}_{\mathrm{OPT}}$ during rewarming. They further suggest that identifying each individual neonate's MAP ${ }_{\mathrm{OPT}}$ with $\mathrm{HVx}$ may serve as a better method than $\mathrm{rSO}_{2}$ alone or rules based on gestational age to select blood pressure goals. 

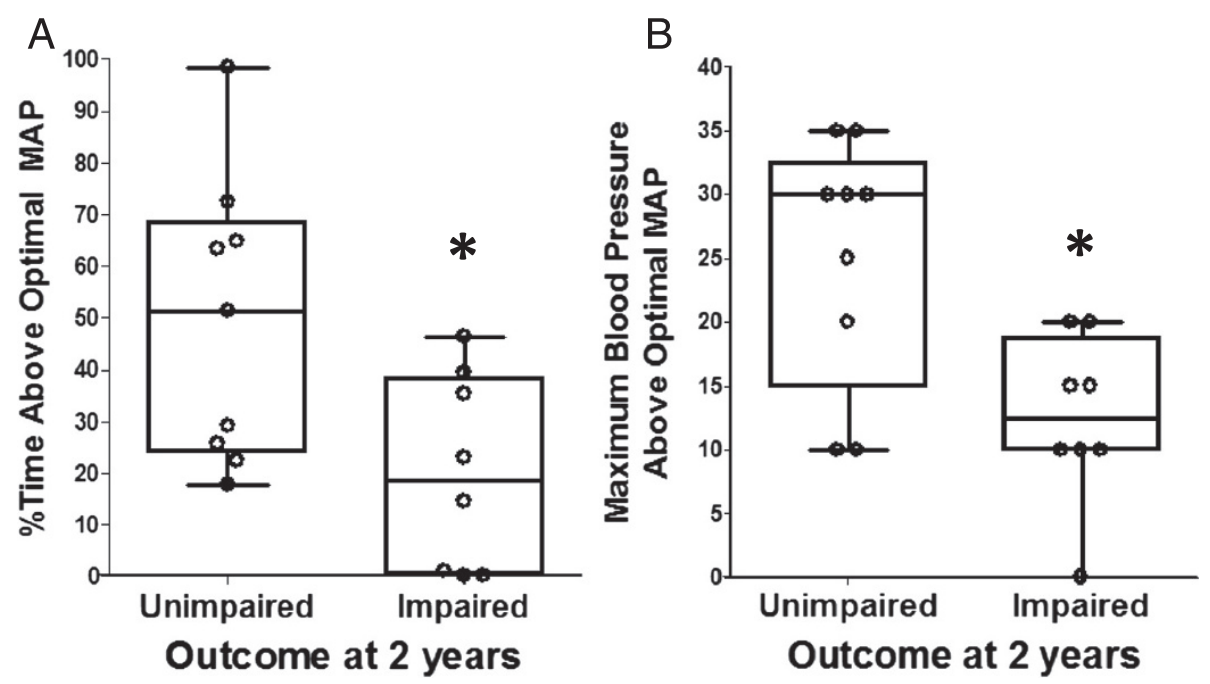

Fig. 5 Blood pressure above the optimal mean arterial blood pressure (MAP) during the neonatal rewarming period in relation to neurodevelopmental outcome at approximately 2 years of age. When compared to children without impairments ( $n=9$; unimpaired), those who developed impairments ( $n=8$; impaired) spent a lower percentage of the rewarming period with blood pressure above optimal MAP $\left({ }^{*} p=0.039 ; \mathbf{a}\right)$ and had less maximal blood pressure deviation above optimal MAP $\left(^{*} p=0.021 ; \mathbf{b}\right)$ during rewarming. Data were analyzed by Mann Whitney rank sum tests. Box plots with whiskers $\left(5^{\text {th }}-95^{\text {th }}\right.$ percentiles $)$ are shown. Each circle represents one child

Although the overall performance of the 19 children evaluated at 2 years was in the average range, the mean cognitive scores were lower than those in normative samples [3,6], and $42 \%$ of the children had impairments in cognitive or motor function. The large variability in performance of the children who had clinical evaluations was likely due to the small number of children in this group. Nine (32\%) children with HIE who received autoregulation monitoring in the NICU did not have neurodevelopmental outcome data available for this study. Nonetheless, the observed associations between neurodevelopmental outcomes and autoregulation in the children with available data carry important considerations for the hemodynamic management of neonatal HIE that deserve further study.

Cerebral NIRS is often used to monitor neonates with HIE during therapeutic hypothermia $[9,10,20-23]$ because invasive neurologic monitoring is generally not feasible in such patients. The predictive value of cerebral oximetry in relation to neurologic outcomes remains unclear in HIE. For neonates with HIE who had selective head cooling, higher cerebral oximetry values during hypothermia were associated with worse outcomes, including death, cerebral palsy, or global delay [22]. In contrast, other studies report that cerebral oximetry cannot predict poor neurologic outcome at 7-10 days of life [21] or severe encephalopathy [23]. Numerous factors that affect cerebral oxygen supply and demand create variability in cerebral oximetry and make immediate interpretation of the readings difficult. These factors include the administration of sedative or anti-epileptic medications, seizures, changes in oxygen supply, hyper/ hypoventilation, and fluctuations in hemoglobin levels. Moreover, the decrease in cerebral metabolic rate during therapeutic hypothermia and the subsequent increase in metabolism during rewarming are confounders. Calculating the cerebral tissue oxygen extraction may offer better correlation with brain injury than regional cerebral oximetry alone [20, 23]. Altered brain oxygen consumption that may be related to dysfunctional autoregulation [24] and regional differences in cerebral perfusion [25] have been described in preterm neonates and neonates with HIE or perinatal arterial ischemic strokes. Methods to assess autoregulation by correlating blood pressure with tissue oxygen levels or oxygen extraction measured by NIRS are being tested in neonates [26-28].

We used the autoregulation metric HVx, which incorporates measures of both oxygenated and deoxygenated hemoglobin. Therefore, HVx should be minimally affected by parameters that change tissue oxygen extraction or supply, including temperature and metabolic demand. This method may enable clinicians to develop an individualized approach for neonates with HIE by identifying and aiming for the $\mathrm{MAP}_{\mathrm{OPT}}$ at which autoregulation is most functional.

Our ability to identify $\mathrm{MAP}_{\mathrm{OPT}}$ in neonates by using HVx showed that MAP $_{\mathrm{OPT}}$ values vary among individuals. Children who developed impairments had significantly higher $\mathrm{MAP}_{\mathrm{OPT}}$ during rewarming from hypothermia than did children who did not develop impairments. Intracranial hypertension raises the limits of 


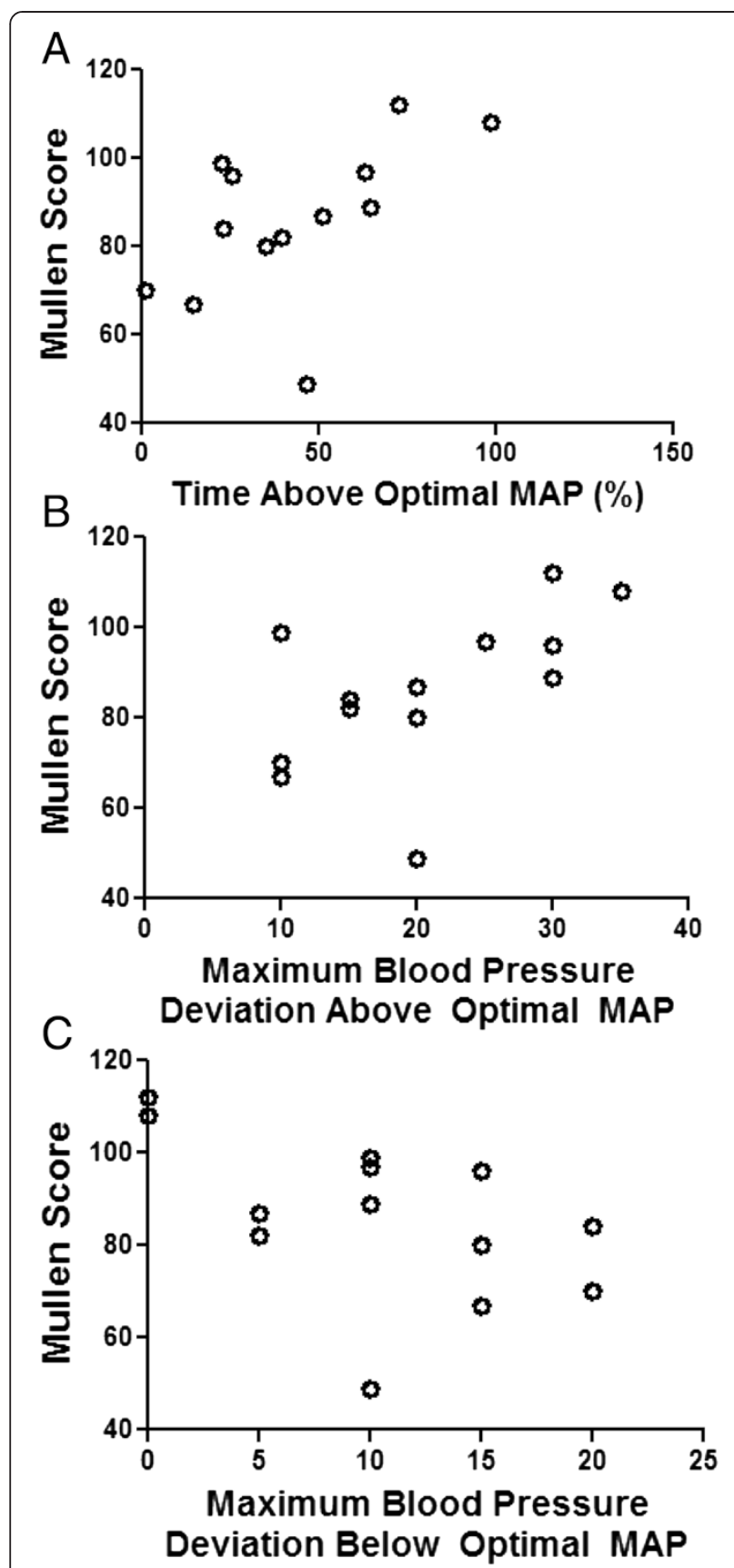

Fig. 6 Blood pressure in relation to the optimal mean arterial blood pressure (MAP) during the neonatal rewarming period and the Mullen score at approximately 2 years of age. Higher Mullen scores correlated with a greater percentage of the rewarming period spent with blood pressure above optimal MAP $(n=13 ; r=0.560, p=0.044 ; \mathbf{a})$ and greater maximal blood pressure deviation above optimal MAP $(n=13 ; r=0.585 ; p=0.035 ; \mathbf{b})$. Lower Mullen scores correlated with greater maximal blood pressure deviation below optimal MAP $(n=13$ $r=-0.563 ; p=0.044 ; \mathbf{c}$ ). Data were analyzed by Spearman correlations. Each circle represents one child blood pressure autoregulation [29]. It is possible that severely injured neonates are at risk of elevated intracranial pressure during rewarming [30], which could shift the blood pressure autoregulation curve to higher pressures and increase $\mathrm{MAP}_{\mathrm{OPT}}$. Identifying $\mathrm{MAP}_{\mathrm{OPT}}$ would be particularly critical in these neonates to clarify hemodynamic goals that support autoregulation.

We also found an association between neurodevelopmental impairment and blood pressure deviation from $\mathrm{MAP}_{\mathrm{OPT}}$ during rewarming. Children with impairments spent more time with blood pressure below $\mathrm{MAP}_{\mathrm{OPT}}$, had greater maximal blood pressure deviation below $\mathrm{MAP}_{\mathrm{OPT}}$, and had greater AUC below MAP $\mathrm{OPT}_{\mathrm{OP}}$ during rewarming than did those without impairments. Greater maximal blood pressure deviation below $\mathrm{MAP}_{\mathrm{OPT}}$ correlated with a lower Mullen Early Learning Composite score. Likewise, having blood pressure that remained above $\mathrm{MAP}_{\mathrm{OPT}}$ during rewarming was associated with less impairment. Children without impairments spent a greater proportion of the rewarming period with blood pressure above $\mathrm{MAP}_{\mathrm{OPT}}$ and had greater blood pressure deviation above $\mathrm{MAP}_{\mathrm{OPT}}$ than did children with impairments. Moreover, more time with blood pressure above $\mathrm{MAP}_{\mathrm{OPT}}$ and greater maximal blood pressure deviation above $\mathrm{MAP}_{\mathrm{OPT}}$ during rewarming correlated with a higher Mullen Early Learning Composite score.

There were no associations between the 2-year neurodevelopmental outcomes and blood pressure deviation from $\mathrm{MAP}_{\mathrm{OPT}}$ during hypothermia or normothermia. The percentages of time that neonates spent with blood pressure below MAP ${ }_{\mathrm{OPT}}$ were similar in the hypothermia, rewarming, and normothermia periods. Several possibilities might explain the association between blood pressure deviation from $\mathrm{MAP}_{\mathrm{OPT}}$ during rewarming and neurodevelopmental outcomes. The inherent risk of secondary neuronal injury may be highest during rewarming. Additionally, severely injured neonates may have less stable cardiovascular regulation and diminished autoregulatory capacity during rewarming. We previously reported that spending more time and having greater blood pressure deviation below $\mathrm{MAP}_{\mathrm{OPT}}$ during rewarming were associated with greater brain injury on MRI $[9,10]$. This finding might be related to an increase in $\mathrm{MAP}_{\mathrm{OPT}}$ during rewarming in severely injured neonates. Rewarming itself might adversely affect cerebral blood flow autoregulation and increase the risk of stroke [31]. Intracranial hypertension and hyperemia can occur in some brain-injured regions during rewarming [30]. Moreover, cytotoxicity from rewarming with resultant neuronal cell death may be enhanced in the post-hypoxic developing brain [32]. Other neural cells also are likely vulnerable to secondary injury after hypoxia in the developing brain. In the $24 \mathrm{~h}$ after rewarming, elevated serum glial fibrillary acidic protein, a biomarker of astrocyte 
injury, was associated with the greatest severity of clinical and MRI markers of brain injury in neonates with HIE [33].

Given the small sample size in this pilot study, we were unable to control for hemoglobin level, $\mathrm{PaCO}_{2}$, or sedation which might affect cerebral blood flow and potentially confound the interpretation of HVx. Neonates did not have any clinical changes during rewarming that would acutely change their hemoglobin level, such as blood transfusion or hemorrhage. Vasoreactivity is affected by changes in $\mathrm{CO}_{2}$ production [34], including those secondary to changing metabolic rate at different temperatures. Nonetheless, $\mathrm{HVx}$ is a useful metric during rewarming because it is derived from both oxygenated and deoxygenated hemoglobin and therefore should be minimally affected by shifts in the oxy-/ deoxyhemoglobin balance with changing temperature and metabolic rate $[9,10,13]$.

The effects of changing ventilatory support during rewarming on $\mathrm{HVx}$ are unclear. Changes in intrathoracic pressure can affect cerebral perfusion pressure [35] and oscillations in arterial oxygen levels from ventilator maneuvers are transmitted to the cerebral microcirculation [36]. Four intubated neonates in this study had adjustments in their ventilator respiratory rate and/or peak inspiratory pressure during rewarming. Because ventilator frequencies are filtered out before calculating HVx, [8] mechanical effects of ventilation should be minimal on HVx unless they substantially increase steady state cerebral venous blood volume. Changes in the inhaled oxygen concentration should also minimally affect $\mathrm{HVx}$, which is derived from the amount of total cerebral hemoglobin and not just the oxyhemoglobin component. On the other hand, it is conceivable that the one neonate who received inhaled nitric oxide during rewarming had increased cerebral delivery of nitrite, which then could have produced cerebral vasodilation. Formal studies to examine the effects of changing ventilator support and oxygen supply on $\mathrm{HVx}$ measurements are warranted.

Regional $\mathrm{SO}_{2}$ and blood pressure based on ga +5 were not associated with neurodevelopmental outcomes in this study. The "normal" MAP for a neonate is often assumed to be the neonate's ga +5 [11], a value that frequently serves as the goal blood pressure for critically ill neonates. Our findings in this pilot study suggest that using autoregulation monitoring to identify hemodynamic goals that support autoregulation may be superior to $\mathrm{rSO}_{2}$ or rules based on gestational age.

While the data suggest that maintaining a patient's blood pressure near MAP ${ }_{\mathrm{OPT}}$ might improve outcome, a cause and effect relationship between blood pressure autoregulation and neurodevelopmental outcome cannot yet be determined in this observational pilot study. The risks of raising a neonate's blood pressure must be considered. While targeting the optimal cerebral perfusion pressure to support autoregulation has not yet been explored in neonates with HIE, it is being evaluated in adult traumatic brain injury [37].

Given the small sample size of this pilot study, we were unable to control for potential confounders such as gender, socioeconomic status and access to therapy services that might affect neurodevelopmental outcome. There are factors in addition to hemodynamic management that may correlate with neurodevelopmental outcomes in HIE, including abnormal EEG and brain imaging [38] and non-neurologic co-morbidities. Also, the type of neonatal cerebral oximetry probe may affect the cerebral oximetry measurements in neonates [39]. Because HVx monitoring could only begin after an arterial blood pressure cannula was established during hypothermia, we analyzed the data as the percentage of the autoregulation monitoring period and normalized the AUC for the duration of monitoring to account for different durations of monitoring during the hypothermia period. Early instability in cerebral autoregulation immediately after the perinatal event was not captured in this study. We were able to monitor $\mathrm{HVx}$ more consistently during rewarming and the first $6 \mathrm{~h}$ of normothermia. HVx measures only the regional frontal cortex and cannot be used to assess other regions of the brain, including those thought to be most at risk from neonatal hypoxic ischemia [40]. Variability in regional brain oxygenation has been reported in models of neonatal HIE, including differences in oxygenation between cortical and thalamic regions [41]. Additionally, we could not validate $\mathrm{HVx}$ against other measures of cerebral blood flow, such as transcranial Doppler, because continuous Doppler is not feasible for 3-4 days in neonates. Nonetheless, $\mathrm{HVx}$ has been validated against laser-Doppler in a swine model of HIE [13], HVx correlates with intracranial pressure-derived autoregulation measures in patients [42], and HVx has been validated against transcranial Doppler in identifying $\mathrm{MAP}_{\mathrm{OPT}}$ during cardiopulmonary bypass [43].

\section{Conclusions}

In this observational pilot study of neonatal HIE and therapeutic hypothermia, we used $\mathrm{HVx}$ monitoring to identify associations between cerebrovascular autoregulatory vasoreactivity during the neonatal rewarming period and 2-year neurodevelopmental outcomes. $\mathrm{MAP}_{\mathrm{OPT}}$ varied among individual neonates and was higher during rewarming in children who developed impairments than in those who did not. Blood pressure deviation below $\mathrm{MAP}_{\mathrm{OPT}}$ during rewarming was associated with greater impairment and lower cognitive 
scores. Although future studies are warranted, our pilot data suggest that individualizing blood pressure goals based on $\mathrm{MAP}_{\mathrm{OPT}}$, especially during the rewarming period, may be superior to $\mathrm{rSO}_{2}$ alone or blood pressure goals based on gestational age to support autoregulation and improve neurodevelopmental outcomes.

\section{Additional files}

Additional file 1: Table S1. Blood pressure data in relation to the optimal mean arterial blood pressure or gestational age, regional cerebral oxygen saturation, and neurodevelopmental disability. (DOCX 19 kb)

Additional file 2: Table S2. Blood pressure in relation to the optimal mean arterial blood pressure and the Mullen score. (DOC 49 kb)

\begin{abstract}
Abbreviations
HIE: Hypoxic-ischemic encephalopathy; HVx: Hemoglobin volume index; MAP OPT: Mean arterial blood pressure at which autoregulatory vasoreactivity is optimal; $\mathrm{rSO}_{2}$ : Regional cerebral oximetry; NIRS: Near-infrared spectroscopy; rTHb: Relative total tissue hemoglobin; NICU: Neonatal intensive care unit; EEG: Electroencephalogram; MRI: Magnetic resonance imaging; AUC: Area under the curve; GMFM: Gross motor function measure; GMFC: Gross motor function classification; ECMO: Extracorporeal membrane oxygenation; $\mathrm{PaCO}_{2}$ : Partial pressure of carbon dioxide in blood.
\end{abstract}

\section{Competing interests}

$J K L$ and FJN previously received funding from Covidien for a separate study.

\section{Authors' contributions}

VJB participated in the design of the study, collection of the neurodevelopmenta outcomes, and helped draft the manuscript. GG participated in the design of the study, collection of the neurodevelopmental outcomes, and reviewed the manuscript. EC participated in the design of the study, collection of the neurodevelopmental outcomes, and reviewed the manuscript. SC helped perform the statistical analysis and interpretation. JJ helped perform the statistical analysis and interpretation and reviewed the manuscript. CP participated in the design of the study and recruitment of participants. RK participated in the autoregulation design and analysis and reviewed the manuscript. RCV participated in the data analysis and reviewed the manuscript. MVJ participated in the design of the study, coordination of the neurodevelopmental outcomes, and reviewed the manuscript. FJN helped conceive of the study, participated in its design and reviewed the manuscript. $\mathrm{JKL}$ helped conceive of the study, participated in the design and autoregulation analysis, and helped to draft the manuscript. All authors read and approved of the final manuscript.

\section{Acknowledgements}

VJB was supported by NIH grant NINDS K12-NS001696 during the writing of this manuscript. JKL was supported by NIH grant K08 NS080984 during the writing of this manuscript. FJN was supported by NIH grant HD070996 during the writing of this manuscript.

\footnotetext{
Author details

${ }^{1}$ Neurology and Developmental Medicine, Kennedy Krieger Institute, Baltimore, MD, USA. ${ }^{2}$ Neurosciences Intensive Care Nursery, Johns Hopkins School of Medicine, Baltimore, MD, USA. ${ }^{3}$ Department of Neurology, Johns Hopkins School of Medicine, Baltimore, MD, USA. ${ }^{4}$ Department of Neuropsychology, Kennedy Krieger Institute, Baltimore, MD, USA. ${ }^{5}$ Division of Perinatal-Neonatal Medicine, Department of Pediatrics, Johns Hopkins School of Medicine, Baltimore, MD, USA. ${ }^{6}$ Center for Child and Community Health Research (CCHR), Department of Pediatrics, Johns Hopkins School of Medicine, Baltimore, MD, USA. ${ }^{7}$ Department of Anesthesiology and Critical Care Medicine, Johns Hopkins School of Medicine, Baltimore, MD, USA. ${ }^{8}$ Hugo Moser Research Institute, Kennedy Krieger Institute, Baltimore, MD, USA. ${ }^{9}$ Department of Neurology and Developmental Medicine, Kennedy Krieger Institute, Johns Hopkins School of Medicine, 801 N Broadway, Baltimore, MD 21205, USA.
}

Received: 3 April 2015 Accepted: 6 October 2015

Published online: 20 October 2015

\section{References}

1. Volpe JJ. Perinatal brain injury: from pathogenesis to neuroprotection. Ment Retard Dev Disabil Res Rev. 2001;7(1):56-64.

2. Graham EM, Ruis KA, Hartman AL, Northington FJ, Fox HE. A systematic review of the role of intrapartum hypoxia-ischemia in the causation of neonatal encephalopathy. Am J Obstet Gynecol. 2008;199(6):587-95.

3. Shankaran S, Pappas A, McDonald SA, Vohr BR, Hintz SR, Yolton K, et al. Childhood outcomes after hypothermia for neonatal encephalopathy. NEJM. 2012;366(33):2085-92.

4. Martin JA, Hamilton BE, Sutton PD, Ventura SJ, Menacker F, Munson ML. Births: final data for 2003. Natl Vital Stat Rep. 2005;54(2):1-116.

5. US Department of Health and Human Services. Centers for Disease Control and Prevention. Economic costs associated with mental retardation, cerebral palsy, hearing loss, and vision impairment - United States, 2003. MMWR Morb Mortality Wkly Rep. 2004;53(03):57-9.

6. Azzopardi D, Strohm B, Marlow N, Brocklehurst P, Deierl A, Eddama O, et al. Effects of hypothermia for perinatal asphyxia on childhood outcomes. NEJM. 2014;371(2):140-9.

7. Chalak LF, Tarumi T, Zhang R. The "neurovascular unit approach" to evaluate mechanisms of dysfunctional autoregulation in asphyxiated newborns in the era of hypothermia therapy. Early Hum Dev. 2014;90:687-94.

8. Lee JK, Kibler KK, Benni PB, Easley RB, Czosnyka M, Smielewski P, et al. Cerebrovascular reactivity measured by near-infrared spectroscopy. Stroke. 2009;40(5):1820-6.

9. Howlett JA, Northington FJ, Gilmore MM, Tekes A, Huisman TAGM, Parkinson C, et al. Cerebrovascular autoregulation and neurologic injury in neonatal hypoxic-ischemic encephalopathy. Pediatr Res. 2013;74(5):525-35.

10. Tekes A, Poretti A, Scheurkogel MM, Huisman TAM, Howlett JA, Alqahtani E, et al. Apparent diffusion coefficient scalars correlate with near-infrared spectroscopy markers of cerebrovascular autoregulation in neonates cooled for perinatal hypoxic-ischemic injury. Am J Neuroradiol. 2015;36(1):188-93.

11. Gretchen CB, Rayannavar AS. Cardiology. In: Engorn B FJ, editor. The Harriet Lane Handbook. 20th ed. Philadephia, PA Saunders, an imprint of Elsevier Inc; 2015. p. 127-71

12. Shankaran S, Laptook AR, Ehrenkranz RA, Tyson JE, McDonald SA, Donovan EF, et al. Whole-body hypothermia for neonates with hypoxicischemic encephalopathy. NEJM. 2005;353(15):1574-84.

13. Larson AC, Jamrogowicz JL, Kulikowicz E, Wang B, Yang Z-J, Shaffner DH, et al. Cerebrovascular autoregulation after rewarming from hypothermia in a neonatal swine model of asphyxic brain injury. J Appl Physiol. 2013;115(10):1433-42.

14. Accardo PJ, Capute AJ. The Capute Scales: Cognitive Adaptive Test/Clinical Linguistic \& Auditory Milestone Scale (Cat/Clams). Portland: Book News, Inc; 2004

15. Visintainer PF, Leppert MO, Bennett A, Accardo PJ. Standardization of the Capute Scales: methods and results. J Child Neurol. 2004;19(12):967-72.

16. Mullen EM. Mullen Scales of Early Learning. San Antonio: Pearson Clinical Asssessments; 1995.

17. Russell DJ, Rosenbaum PL, Wright M, Avery LM. Gross Motor Function Measure (GMFM-66 and GMFM-88) User's Manual 2nd Ed. London: MacKeith Press; 2013.

18. Palisano R, Rosenbaum P, Walter S, Russell D, Wood E, Galuppi B. Development and reliability of a system to classify gross motor function in children with cerebral palsy. Dev Med Child Neurol. 1997;39(4):214-23.

19. Beckung E, Hagberg G. Correlation between ICIDH handicap code and Gross Motor Functional Classification System in children with cerebral palsy. Dev Med Child Neurol. 2000;42:669-73.

20. Massaro AN, Bouyssi-Kobar M, Chang T, Vezina LG, du Plessis AJ, Limperopoulos C. Brain perfusion in encephalopathic newborns after therapeutic hypothermia. Am J Neuroradiol. 2013;34(8):1649-55.

21. Shellhaas RA, Thelen BJ, Bapuraj JR, Burns JW, Swenson AW, Christensen MK, et al. Limited short-term prognostic utility of cerebral NIRS during neonatal therapeutic hypothermia. Neurology. 2013;81(3):249-55.

22. Ancora G, Maranella E, Grandi S, Sbravati F, Coccolini E, Savini S, et al. Early predictors of short term neurodevelopmental outcome in asphyxiated cooled infants. A combined brain amplitude integrated electroencephalography and near infrared spectroscopy study. Brain Dev. 2013;35(1):26-31 
23. Wintermark P, Hansen A, Warfield SK, Dukhovny D, Soul JS. Near-infrared spectroscopy versus magnetic resonance imaging to study brain perfusion in newborns with hypoxic-ischemic encephalopathy treated with hypothermia. Neurolmage. 2014;85(1):287-93.

24. De Vis JB, Petersen ET, Alderliesten T, Groenendaal F, de Vries LS, van Bel F, et al. Non-invasive MRI measurements of venous oxygenation, oxygen extraction fraction and oxygen consumption in neonates. Neurolmage. 2014;95:185-92.

25. De Vis JB, Petersen ET, Kersbergen KJ, Alderliesten T, de Vries LS, van Bel F, et al. Evaluation of perinatal arterial ischemic stroke using noninvasive arterial spin labeling perfusion MRI. Pediatr Res. 2013;74(3):307-13.

26. Verhagen EA, Hummel LA, Bos AF, Kooi EMW. Near-infrared spectroscopy to detect absence of cerebrovascular autoregulation in preterm infants. Clin Neurophysiol. 2014;125(1):47-52.

27. Hahn $\mathrm{GH}$. Testing impact of perinatal inflammation on cerebral autoregulation in preterm neonates: evaluation of a noninvasive method. Dan Med J. 2013;60(4):B4628.

28. Baerts W, van Bel F, Thewissen L, Derks JB, Lemmers PMA. Tocolytic indomethacin: effects on neonatal haemodynamics and cerebral autoregulation in the preterm newborn. Arch Dis Child Fetal Neonatal Ed. 2013;98(5):F419-23.

29. Brady KM, Lee JK, Kibler KK, Easley RB, Koehler RC, Czosnyka M, et al. The lower limit of cerebral blood flow autoregulation is increased with elevated intracranial pressure. Anesth Analg. 2009;108(4):1278-83.

30. lida K, Kurisu K, Arita K, Ohtani M. Hyperemia prior to acute brain swelling during rewarming of patients who have been treated with moderate hypothermia for severe head injuries. J Neurosurg. 2003;98(4):793-9.

31. Joshi B, Brady K, Lee JK, Easley B, Panigrahi R, Smielewski P, et al. Impaired autoregulation of cerebral blood flow during rewarming from hypothermic cardiopulmonary bypass and its potential association with stroke. Anesth Analg. 2010;110(2):321-8.

32. Wang B, Armstrong JS, Lee J-H, Bhalala U, Kulikowicz E, Zhang $\mathrm{H}$ et al. Rewarming from therapeutic hypothermia induces cortical neuron apoptosis in a swine model of neonatal hypoxic-ischemic encephalopathy. J Cereb Blood Flow Metab. 2015;Jan 7:Epub ahead of time

33. Ennen CS, Huisman TAGM, Savage WJ, Northington FJ, Jennings JM, Everett $A D$, et al. Glial fibrillary acidic protein as a biomarker for neonatal hypoxic-ischemic encephalopathy treated with whole-body cooling. Am J Obstet Gynecol. 2011;205(3):251-e1-7.

34. Pollock JM, Deibler AR, Whitlow CT, Tan H, Kraft RA, Burdette JH, et al. Hypercapnia-induced cerebral hyperperfusion: an underrecognized clinical entity. AJNR Am J Neuroradiol. 2009;30(2):378-85.

35. Kiehna EN, Huffmyer UL, Thiele RH, Scalzo DC, Nemergut EC. Use of the intrathoracic pressure regulator to lower intracranial pressure in patients with altered intracranial elastance: a pilot study. J Neurosurg. 2013;1 19(3):756-9.

36. Klein KU, Boehme S, Hartmann EK, Szczyrba M, Heylen L, Liu T, et al. Transmission of arterial oxygen partial pressure oscillations to the cerebral microcirculation in a porcine model of acute lung injury caused by cyclic recruitment and derecruitment. Br J Anaesth. 2013;110(2):266-73.

37. Dias C, Silva MJ, Pereira E, Monteiro E, Maia I, Barbosa S, et al. Optimal Cerebral Perfusion Pressure Management at Bedside: A Single-Center Pilot Study. Neurocrit Care. 2015;23(1):92-102.

38. Jose A, Matthai J, Paul S. Correlation of EEG, CT, and MRI Brain with Neurological Outcome at 12 Months in Term Newborns with Hypoxic Ischemic Encephalopathy. J Clin Neonatol. 2013;2(3):125-30.

39. Dix LML, van Bel F, Baerts W, Lemmers PMA. Comparing near-infrared spectroscopy devices and their sensors for monitoring regional cerebral oxygen saturation in the neonate. Pediatr Res. 2013;74(5):557-63.

40. Ghei SK, Zan E, Nathan JE, Choudhri A, Tekes A, Huisman TAGM, et al. MR imaging of hypoxic-ischemic injury in term neonates: pearls and pitfalls. Radiographics. 2014;34(4):1047-61.

41. Manole MD, Kochanek PM, Bayir H, Alexander H, Dezfulian C, Fink EL, et al. Brain tissue oxygen monitoring identifies cortical hypoxia and thalamic hyperoxia after experimental cardiac arrest in rats. Pediatr Res. 2014;75(2):295-301.

42. Zweifel C, Castellani G, Czosnyka M, Helmy A, Manktelow A, Carrera E, et al Noninvasive Monitoring of Cerebrovascular Reactivity with Near Infrared Spectroscopy in Head-Injured Patients. J Neurotrauma. 2010;27(11):1951-8.

43. Easley RB, Kibler KK, Brady KM, Joshi B, Ono M, Brown C, et al. Continuous cerebrovascular reactivity monitoring and autoregulation monitoring identify similar lower limits of autoregulation in patients undergoing cardiopulmonary bypass. Neurol Res. 2013;35(4):344-54.

\section{Submit your next manuscript to BioMed Central and take full advantage of:}

- Convenient online submission

- Thorough peer review

- No space constraints or color figure charges

- Immediate publication on acceptance

- Inclusion in PubMed, CAS, Scopus and Google Scholar

- Research which is freely available for redistribution

Submit your manuscript at www.biomedcentral.com/submit 